observer and interobserver variability. ${ }^{4}$ When the cardiotocogram is abnormal fetal blood sampling to assess the severity of fetal acidosis should be performed.

R A K JAIYESIMI

L C H TANG

Queen Mary's University Hospital,

London SW15 5PN

1 Ennis $M$, Vincent CA. Obstetric accidents: a review of 64 cases. BrMed f 1990;300:1365-7. (26 May.)

2 Nelson KB, Ellenberg JH. Antecedents of cerebral palsy. Multivariate analysis of risk. $N$ Engl f Med 1986;315:81-6.

3 Paneth N. Birth and origins of cerebral palsy. N Engl f Med 1986;315:124-6.

4 Nielsen PV, Stigsby B, Nickelsen C, Nim J. Intra- and inter observer variability in the assessment of intrapartum cardiotocograms. Acta Obstet Gynaecol Scand 1987;66:421-4.

SIR,-While inadequacies in fetal monitoring, forceps management, and supervision by senior staff were found to be common to most of the 64 cases of obstetric accident reviewed by Ms M Ennis and $\mathrm{DrCA}$ Vincent and these conditions could not have increased the possibility of a safe delivery, the design of this study does not permit the conclusion that they were necessarily the cause of the disastrous outcomes.' The generalisation that disastrous outcomes would be avoided if these inadequacies were corrected is even less appropriate. Before identifying conditions as causes of death or damage one has to measure whether or not they were present also in cases of healthy survival.

In the opinion of one or a small number of experts fetal monitoring was inadequate, either because it was not carried out or because interpretation of the electronic traces did not prompt appropriate action. But correct interpretation of traces is notoriously difficult because there is a wide overlap between the recorded responses of healthy and distressed fetuses. Wide variation in interpretation has been reported between experienced observers, ${ }^{2}$ and interpretation of a monitor's traces is often contradicted by analyses of blood samples taken concurrently from the fetal scalp. ${ }^{3}$ The present study does not mention results of such blood tests.

Whether or not a different interpretation of an electronic trace would have prevented disaster in the particular cases reviewed, obstetricians have not been able to show that, in general, electronic fetal monitoring has made birth safer. ${ }^{+5}$ The benefit of a lower rate of neonatal neurological damage found in one study after continuous monitoring compared with intermittent monitoring had disappeared by early childhood, and the incidence of cerebral palsy was not reduced in the group randomised to electronic monitoring. ${ }^{6}$

In most cases electronic monitoring confines the mother to bed, and because of her immobility she is more aware of her pain, which is often increased by oxytocin administration. She is more likely to be given epidural anaesthesia and thus more likely to need a forceps delivery. Certainly, obstetricians should learn how to apply forceps effectively if they are needed but the need is often created by earlier obstetric procedures as is the fetal distress which monitoring aspires to detect.

Correcting the inadequacies identified in this study should help to reduce the number of events judged as accidents by expert obstetricians but would reduce only marginally the total of deaths and damage associated with birth. The cause of many of these lies, ironically, in obstetric intervention itself.

University Hospital

Queen's Medical Centre

Nottingham NG7 2UH

1 Ennis $M$, Vincent CA. Obstetric accidents: a review of 64 cases. BrMed f 1990;300:1365-7. (26 May)

2 Lotgering F, Wallenburg $\mathrm{H}$, Schouten $\mathrm{H}$. Interobserver and intraobserver variation in the assessment of antepartum cardiotocograms. Am f Obstet Gynecol 1982;144:701-5.
3 Godfrey, KA. Interventions in labour: machines in labour. In: Marsh GN, ed. Modern obstetrics in general practice. Oxford: Oxford University Press, 1985:313.

4 Prentice A, Lind T. Fetal heart rate monitoring during labourtoo frequent intervention, too little benefit? Lancet 1987;ii: 1375-7.

5 Banta, D, Thacker S. Assessing the costs and benefits of electronic fetal monitoring. Obstet Gynecol Surv 1979;34:627. 42 .

6 MacDonald D, Grant A, Sheridan-Pereira M, Boylan P, Chalmers I. The Dublin randomised controlled trial of intrapartum fetal heart rate monitoring. Am f Obstet Gynecol 1985;152:524-39.

7 Grant A, O'Brien N, Joy M-T, Hennessy E, MacDonald D. Cerebral palsy among children born during the Dublin randomized controlled trial of intrapartum monitoring. Lancet 1989;ii:1233-6.

SIR, - Ms M Ennis and Dr C A Vincent emphasise lack of fetal monitoring in cases that led to litigation in obstetrics.' They fail, however, to mention that none of the nine randomised controlled trials (comprising over 54000 patients) of continuous electronic fetal monitoring in labour showed any benefit in perinatal mortality and morbidity, $\mathrm{pH}$ values of blood from the umbilical cord, and Apgar scores. The largest trial included follow up of babies at 1 and 4 years and showed no difference between the study group and control group. ${ }^{2}$ There was also wide disagreement concerning both interpretation of the cardiotocogram and strategies for intervention in two European studies by experts on perinatal monitoring. ${ }^{3}$

The American College of Obstetricians and Gynecologists informed its 35000 members last year that, having carefully considered all the evidence from the monitoring trials, it concluded that intermittent auscultation and continuous electronic monitoring are equivalent methods of fetal surveillance in labour, even in high risk cases. ${ }^{4}$ In cases of prematurity a randomised study of fetal surveillance in labour has failed to show any improvement in the immediate outcome ${ }^{5}$ or in the neurological development at 18 months $^{6}$ between infants monitored electronically and those monitored by auscultation.

Surely it is time that the courts, lawyers, and their medical advisers in this country based statements about continuous electronic fetal monitoring in labour on accurate scientific facts.

JOHN KELLY

Birmingham Maternity Hospital,

Queen Elizabeth Medical Centre,

Birmingham B15 2TG

1 Ennis $M$, Vincent CA. Obstetric accidents: a review of 64 cases. BrMed f 1990;300:1365-7. (26 May.)

2 Grant A, Joy MT, O'Brien N, Hennessy E, MacDonald D. Cerebral palsy among children born during the Dublin randomised trial of intrapartum monitoring. Lancet 1989;ii: 1233-5.

3 Kelly J. Doctors and medical negligence. Br Med f 1990;300:747. 4 American College of Obstetricians and Gynecologists. Standards for obstetric-gynecologic services 1989 . 7th ed. Washington, DC: ACOG, 1989:35-7.

5 Luthy DA, Shy KK, van Belle G, et al. A randomized trial of electronic fetal monitoring in preterm labour. Obstet Gynecol electronic fetal

6 Shy KK, Luthy DA, Bennett FC, et al. Effects of electronic fetalheart rate monitoring, as compared with periodic auscultation,
on the neurologic development of premature infants. $N E n g l f$ on the neurologic developi
Med 1990;322:588-93.

\section{Central pain}

SIR,-In its commonest form, central post-stroke pain (formerly known as the thalamic syndrome probably afflicts $2 \%$ of all stroke victims. As Dr L S Illis says in his editorial the pathophysiological division (if any) between central and peripheral neurogenic pain is blurred. ${ }^{\prime}$ The two categories together may account for as many as 500000 cases of chronic pain within the United Kingdom at any one time; the commonest form is postherpetic neuralgia, followed by painful diabetic neuropathy.

Diagnosis is indeed all important and relatively simple. ${ }^{2}$ These pains are often described as burning (more articulately, scalding or ice burn) and less often as shooting or stabbing, or both. When allodynia (production of pain by a non-noxious phasic mechanical stimulus such as contact with clothes but not by firm pressure) occurs it is pathognomonic. There is, as Dr Illis says, a partial somatosensory deficit (except in trigeminal neuralgia) which may easily be missed in segmental conditions such as postherpetic neuralgia. Perhaps most importantly, these pains are resistant to conventional analgesia, but I hope that this feature will not be used diagnostically because treatment with amitriptyline is most effective when given early. The role of anticonvulsants is emphatically secondary to that of amitriptyline except in trigeminal neuralgia. A recent double blind trial suggests that carbamazepine is of no value at all in central pain.

Pain Research Institute,

DAVID BOWSHER

\section{Walton Hospital,}

Liverpool L9 IAE

1 Illis LS. Central pain. Br Med f 1990;300:1284-6. (19 May.)

2 Bowsher D. Pain as a neurological emergency. In: Neurological emergencies in medical practice. Beckenham: Croom Helm, 1988:216.

3 Leijon G, Boivie J. Central post-stroke pain-a controlled trial of amitriptyline and carbamazepine. Pain 1989;36:27.

\section{Primary survey in major trauma}

SIR, - The spectre of precipitating quadriparesis in a patient with a damaged cervical spine is obviously horrific. Messrs Peter Driscoll and David Skinner suggest that "the in line stability of the neck must be maintained" during intubation and that orotracheal rather than nasotracheal intubation is preferred. ${ }^{\prime}$ I assume that they mean some form of traction, even if only temporarily applied. But axial traction can aggravate displacement at fracture sites during orotracheal intubation of severely injured patients-nasotracheal intubation without axial traction is recommended if instability is suspected. ${ }^{2}$

Fibreoptic intubation of the awake patient with a cervical injury or a full stomach, or both, has been advocated, ${ }^{34}$ but this procedure often causes coughing and bucking and I cannot believe that it is a good idea when the spine is genuinely unstable.

I have not found any published account of spinal cord damage caused by intubation, and a request for details of such cases from other members of the British Cervical Spine Society at a meeting in Edinburgh in 1988 produced no result. It seems possible that cord damage during tracheal intubation of patients with unstable cervical spines is largely a theoretical problem that should not inhibit resuscitators intending to intubate the trachea in an emergency.

IAN CALDER

National Hospitals for Nervous Diseases,

London WCIN 3BG

1 Driscoll P, Skinner D. ABC of major trauma. Initial assessment and management. I. Primary survey. Br Med $\mathcal{F}$ 1990;300: 1265-7. (12 May.)

2 Bivins HG, Ford S, Bezmalinovic $Z$, et al. The effect of axial traction during orotracheal intubation of the trauma victim with an unstable cervical spine. Ann Emerg Med 1988;17:25-9.

3 Delaney KA, Hessler R. Emergency flexible fiberoptic nasotracheal intubation: a report of 60 cases. Ann Emerg Med 1988;17:919-25

4 Ovassapian A, Krejcie TC, Yelich SH, Dykes MHM. Awake fiberoptic intubation in the patient at high risk of aspiration. Br F Anaesth 1989;62:13-6.

\section{Prevalence of asthma in children}

SIR, - The recent report from Dr P G J Burney and colleagues suggests a real increase in the prevalence of asthma over time among children in England.' We have found a similar increase in symptoms among an adolescent population in rural 
New Zealand. In 1989 we performed a survey of asthma symptoms among a biracial, rural school population of 499 subjects aged 12-18. The survey questions and technique were the same as those used 14 years previously by Stanhope et al when examining a similar population of 741 students at the same school.

The prevalence of reported wheeze had increased significantly from $26 \cdot 2 \%$ to $34.0 \%(p=0.01)$, as had wheeze within the past 12 months from $20 \cdot 1 \%$ to $25.5 \%(\mathrm{p}=0.05)$. The prevalence of reported asthma had also increased from $8 \cdot 0 \%$ to $13 \cdot 3 \%$ $(p<0.005)$, but to a lesser extent than a history of wheeze.

Among those without a previous diagnosis of asthma the frequency of wheezing occurring only with colds had not changed significantly $(13.6 \%$ to $12 \cdot 6 \%)$. By comparison wheeze unassociated with colds and without a previous label of asthma had increased significantly from $4.6 \%$ to $8.0 \%$ $(p=0.01)$. Reported bronchitis, however, had not changed $(16 \cdot 2 \%$ to $16 \cdot 1 \%)$.

For each comparison we adjusted for differences in age, sex, and race by multiple logistic regression.

Between our two adolescent populations there has been a significant increase in the prevalence of wheeze over the past 14 years. This increase is not explained simply by a change in labelling. The prevalence of diagnosed asthma has increased, but less so than the increase in wheeze, and there has been no corresponding fall in reported bronchitis.

Greater medical and public awareness of asthma may explain the increasing prevalence of reported asthma. ${ }^{3}$ We have considered the possibility that the recognition and reporting of wheeze might also have increased for the same reasons. Among those without a diagnosis of asthma wheezing unrelated to colds increased significantly while wheezing related only to colds did not. This suggests that the increased prevalence of reported wheeze over the past 14 years is not explained by a change in public awareness.

The finding of an increased prevalence of wheez ing in this New Zealand adolescent group lends further support to the likelihood that the true prevalence of asthma has increased. As Dr Burney and colleagues suggest, this might contribute to increasing hospital admissions and mortality from asthma. While comments on the reasons for this must be almost entirely speculative, the possible associations with changing patterns of treatmen need to join other more or less fanciful hypotheses awaiting further investigation.

Department of Medicine

Wellington School of Medicine,

PO Box 7343 Wellington South,

New Zealand

1 Burney PGJ, Chinn S, Rona RJ. Has the prevalence of asthm increased in children? Evidence from the national study of health and growth 1973-86. Br Med f 1990;300:1306-10. (19 May.)

2 Stanhope JM, Rees RO, Mangan AJ. Asthma and wheeze in New Zealand adolescents. NZ Med f 1979;90:179-82.

3 Hill $R$, Williams J, Tattersfield A, Britton J. Change in use of asthma as a diagnostic label for wheezing illness in schoolchildren. Br Med f 1989;299:898.

\section{Treatment of a pancreatic tumour secreting parathyroid hormone related protein}

SIR,-Dr D Wynick and colleagues report the successful treatment with a somatostatin analogue of a patient with hypercalcaemia due to the release of parathyroid hormone related protein from a pancreatic endocrine tumour.' We would like to add our experience with octreotide to this.

A 42 year old woman was admitted with a three year history of intermittent episodes of vomiting
On examination she was found to have an abdominal mass and was hypercalcaemic. At laparotomy a large retroperitoneal tumour in the area of the pancreas was found as well as liver metastases. A biopsy was performed, and histology was consistent with a neuroendocrine tumour. Prednisolone was prescribed, but she was lost to follow up. Twelve months later she was referred to our unit because of uncontrolled hypercalcaemia. She was cushingoid, and a mass was palpable in the epigastrium. Her corrected serum calcium concentration was $4.94 \mathrm{mmol} / \mathrm{l}$ and she had a low serum concentration of immunoreactive parathyroid hormone but greatly raised cyclic AMP excretion. Her serum parathyroid hormone related protein concentration was $2.38 \mu \mathrm{g} / \mathrm{l}$ (normal value $<1 \cdot 5 \mu \mathrm{g} / \mathrm{l})$. Abdominal computed tomography showed a mass in the pancreas and a single liver metastasis. Bone scintigraphy yielded normal results, and the bone marrow biopsy specimen showed no evidence of malignant infiltration but showed considerably increased osteoclastic bone resorption. Plasma concentrations of vasoactive intestinal polypeptide, gastrin, glucagon, calcitonin, and neurotensin were normal. Urinary 5-hydroxyindoleacetic acid concentration was moderately raised whereas the concentrations of catecholamine excretion products were within the normal range.

She was treated with repeated infusions of pamidronate $60 \mathrm{mg}$, but this failed to normalise the serum calcium concentration. A trial of interferon alfa ( 3 million units thrice weekly) was ineffective, but octreotride $50 \mu \mathrm{g}$ subcutaneously twice daily improved control with the serum calcium concentration fluctuating around $3.0 \mathrm{mmol} / \mathrm{l}$. Selective angiography confirmed a single liver lesion, and an attempt was made to control the hypercalcaemia by surgical debulking and a $10 \mathrm{~cm}$ mass was resected from the liver. Immunohistochemistry showed the tumour cells to have strong parathyroid hormone related protein staining. Postoperatively, however, the calcium concentration again became raised but was finally controlled by increasing the octreotide to $100 \mu \mathrm{g}$ twice daily. She remained well and normocalcaemic receiving this dose of octreotide 18 months after her most recent surgery.

D DODWELL H GURNEY H SCARFFE

Department of Medical Oncology Christie Hospital,

Manchester

Department of Animal Physiology and Nutrition University of Leeds, Leeds

1 Wynick D, Ratcliffe WA, Heath DA, Ball S, Barnard M, Bloom SR. Treatment of a malignant pancreatic endocrine tumour secreting parathyroid hormone related protein. $\mathrm{Br}$ Med $\mathcal{f}$ 1990;300:1314-5. (19 May.)

\section{Depression and the menopause}

SIR,-By conceding that oestrogens may be helpful for depressed mood while depressive disorder requires psychiatric treatment ${ }^{1}$ Drs Dennis Gath and Susan Iles show but a modest shift from the traditional psychiatric opinion that oestrogens are irrelevant to either the causation or the treatment of depression in women. ${ }^{2}$ Gynaecologists treating depressed women at the climacteric would fundamentally disagree with this view.

The writers pose three questions about depression "around the menopause." Is it more common? Is it due to lack of oestrogen? Does it need oestrogen replacement? Their denial of these points needs to be contested.

There is no dispute that there is an increased incidence of depression in women compared with men and that this excess begins from puberty ${ }^{3}$ and is most apparent at times of hormonal fluctuations such as occur in the premenstrual phase, the postnatal months, and the years of the climacteric. It is also relevant that depression is uncommon in the last trimester of pregnancy, when oestrogen concentrations are high and stable.

We as gynaecologists accept entirely the environmental contribution to depression but are saddened by the failure of psychiatrists who treat these women to recognise that there is often a hormonal component and that oestrogen therapy will relieve their misery more effectively and safely than psychoactive drugs or electroconvulsive therapy. It is truly an aspect of the health care of women where there is little overlap between the two specialties.

The severe cyclical depression of the premenstrual syndrome has been shown in placebo controlled trials to respond to oestrogens, both oestradiol implants ${ }^{4}$ and oestradiol patches, ${ }^{5}$ at a dose high enough to suppress the hormonal fluctuations of the ovarian cycle.

Similarly, climacteric depression responds to percutaneous oestrogens, ${ }^{6}$ which are most effective in perimenopausal patients who were still having periods. In postmenopausal women the response is no better than that to a placebo. A major European study showed that climacteric depression was most severe in the two to three years before the cessation of periods. ' There is thus a double load for the patient to bear as cyclical premenstrual depression characteristically becomes worse with age as it blends into the years of most severe climacteric depression.

There is now a growing body of evidence to indicate that the affective components of the premenstrual and the climacteric syndromes usually respond well to oestrogen therapy. In most cases the commonplace habit of giving antidepressants and tranquillisers before trying oestrogen therapy is wrong. The difference between depression and depressed mood is irrelevant to women suffering from both the climacteric and inappropriate psychoactive drugs. But the sceptics need to be convinced, and some interspecialty collaborative research is urgently required to assess the true value of oestrogen therapy, as prescribed by gynaecologists, ${ }^{8}$ in the various types of depression as defined and classified by psychiatrists.

JOHN W W STUDD NEALE R WATSON

King's College Hospital,

London SES

University College Hospital

London WC1

1 Gath D, Iles S. Depression and the menopause. $\mathrm{Br}$ Med $f$ 1990;300:1287-8. (19 May.)

2 Jenkins R, Clare AW. Women and mental illness. Br Med $f$ 1985;291:1521-2.

3 Jorm AF. Sex and age differences in depression. Aust $N Z \mathcal{J}$ Psychiatry 1987;21:46-53.

4 Magos AL, Brincat $M$, Studd JWW. Treatment of the premenstrual syndrome by subcutaneous oestradiol implants and cyclical norethisterone: placebo controlled study. $\mathrm{Br} \mathrm{Med} \mathcal{J}$ 1986;292:1629-37.

5 Watson NR, Studd JWW, Baber R, Garnett T. The treatment of the pre-menstrual syndrome by suppression of ovulation with transdermal oestradiol patches. Lancet 1989; i:730-2.

6 Montgomery JC, Appleby L, Brincat M, et al. Effect of oestrogen and testosterone implants on psychological disorders of the climacteric. Lancet 1987; i:297-9.

7 Jaszman L. Epidemiology of the climacteric complaints. Horm Res 1973:2:220-34.

8 Studd JWW, Whitehead MI. The menopause. Oxford: Blackwell, 1988.

\section{Maternal and fetal screening for antenatal care}

SIR, - While appreciating the problems of writing a general article on maternal and fetal screening for antenatal care, we feel that Dr M J V Bull's article requires comment. 